\title{
The Impact of the Future Fluctuating Energy Consumption on a District Heating System: Case Study of Omsk and Krasnoyarsk Cities
}

\author{
Stanislav CHICHERIN ${ }^{1}{ }^{*}$, Andrey ZHUIKOV ${ }^{2}$, Mikhail KOLOSOV $^{3}$, Lyazzat JUNUSSOVA ${ }^{4}$, \\ Madina ALIYAROVA ${ }^{5}$, Aliya YELEMANOVA ${ }^{6}$ \\ ${ }^{1}$ Omsk State Transport University (OSTU), 644046, 35, Marx Avenue, Omsk, Russia \\ ${ }^{2,3}$ Siberian Federal University, 660041, Svobodny Ave. 79, Krasnoyarsk, Russia \\ ${ }^{4-6}$ Non-profit JSC, Almaty University of Power Engineering and Telecommunications, Almaty, Kazakhstan
}

\begin{abstract}
Temperature difference between supply and return distribution medium (water) is a vital factor when assessing the efficiency of a district heating (DH) substation. An accounting for fluctuations and differences of the heat consumption/generation is the key problem in planning DH system operation. The influence of the fluctuating energy consumption on a DH system was studied with actual data, using the DH systems of the Russian cities Krasnoyarsk and Omsk as a case study. Information is visualized in the form of graphs and charts, orderly and clearly comparing certain points. The data includes supply and return temperatures, and heat demand. Clearly visible state of high return temperatures induces more bottleneck problems as the flow increases. At the same time, in 2019, the total heat demand was $21008 \mathrm{MW}$. This is more than $5 \%$ than in 2020 , assuming $100 \%$ of consumers connected. The reasons for this trend are: decreasing total housing area, no incentive for the buildings in newly built-up areas to be connected to the DH system, poor service motivating business facilities to disconnect from the system. When the primary energy consumption related to the warmer climate and behaviour of business sector decreases, the DH system requires renovation. It is possible to reduce network return temperature during some months of the year. The reason is that, a high temperature difference is essential to maintain high efficiency and minimize fuel and pumping cost, it also enables more customers to be connected to a DH system without increasing pipe dimensions of a network.
\end{abstract}

Keywords - Demand; district heating; efficiency; heat consumption; load; optimization; space heating; supply; temperature; thermal

\section{INTRODUCTION}

Brange et al. [1] mention return and supply temperatures as indicators of a DH system performance. Indeed, the temperature difference between supply and return distribution medium (water) is a vital factor when assessing the efficiency of a DH substation. If the return temperature is low, this means that more thermal energy has been transferred from the $\mathrm{DH}$ network supply line to the building space heating $(\mathrm{SH})$ system. An accounting for fluctuations and differences of the heat consumption/generation and also accounting for evolution and uncertainty in the network parameters is the key problem in planning DH system operation

* Corresponding author.

E-mail address: man_csv@hotmail.com 
over a sufficiently long-time horizon (year and beyond) [2]. Small variations in the relative heating ratios may result into drastic changes in diversity, and therefore efficiency [3].

The suggested in [4] three-pipe option utilises one supply pipe and two return pipes, whereby one return pipe is in use when energy demand occurs, referred to as the delivery flow, while the other return pipe is in use when there is no energy demand, referred to as the recirculation flow. The latter of these is mostly related to domestic hot water (DHW) usage profile, for example, inhabitants usually have a shower in the morning, before they go out. This results into stresses on a DH system, as there is a lot of heat demand required to provide energy all the showers almost simultaneously. To cover heat-demand peaks, more hot water has to be released from a DH plant. If a DH system is properly dimensioned, it cannot only veer an unfair distribution of heat, but it can also ensure ample flexibility to cut peaks [5]. Coss et al. [6] quantify a relationship: a building structure with $50 \%$ public buildings (in terms of total yearly heat demand) shows a peak load which is only about $80 \%$ of the one with $20 \%$ public buildings. Shaving energy peaks decreases the cost for both the network operator and the consumer [7]. In [8], two types of additional energy consumption including pumping power and heat loss during thermal energy transmission are studied. In paper [9], energy demand of a DH plant is just set constant in order to consider the potential heat losses of a DH network. Noussan et al. [10] detail the operation analysis of existing DH systems considering actual data and detailed time steps. The statistical data in [11] has been elicited during the year 2012 and the experiment time accounts 366 days. In [12], data on representative DH systems in Zagreb and Aalborg were obtained. Brange et al. [13] claim a so called "bottleneck" problem ignoring consideration of actual data. Romanchenko et al. [14] discovered an increasing value of CHP plants with flexible power-to-heat ratio. In Tianjin Eco-City, China the system includes generation facilities such as ground source heat pumps, thermal energy storage, and CHP plants [15]. In [16], authors analyse a methodology for expansion planning in an existing DH system based on the concept of integrated resource planning. Spatial expansion topology is covered by Delangle et al. [17] as well. Using a mixed-integer linear programming approach, their [17] model is able to minimize the future energy center operation by choosing the best combination of technologies to reach the set goal. In del Hoyo et al. research [18], detailed models are presented; their validation against $\operatorname{Apros}^{\circledR}$ and $I D A-I C E \AA$ Software is also provided. Schweiger et al. [19] apply for their framework the high-level equation-based modelling software - Modelica. Badami et al. [20] declare using a Monte Carlo Module. Dahl et al. [21] develop a heat load forecast model with dynamic weather-based uncertainties. Shan et al. [22] also reflect the dependence on the outside temperature though the dependence of failure justification. On the other hand, as stated by Wang et al. [23] supply and return water temperature distribution prediction for a real practice network can be more reliable on steady state conditions. For instance, in [11], the system operation process transitions is studied on the basis of experimental data from system in Rzeszow, Poland. To predict a value of thermal load, Geysen et al. [24] establish feature set that considers timing data, temperature prediction, statistics on heat demands and control signals. The SH system return temperature as well as the temperature variations of the air indoor is included in a lumped capacitance simulation [25]. As a first estimate, Zarin Pass et al. [3] input fixed heating and cooling supply temperatures and constant network temperatures, although a more accurate analysis could be done.

Besides, electricity consumption has to be increased to ensure proper pressure level over the network; again, the temperature of the water leaving a DH plant may be increased. For instance, if the flow rate varies circa 3.5 times ranging the extremes $\left(300-1100 \mathrm{~m}^{3} / \mathrm{h}\right)$, the pressure at a DH plant will rise from 3.5 to 8.5 bars [26]. Tunzi et al. [27] discuss a 
'motivation tariff' providing a discount of the end-user's energy bill for each $1^{\circ} \mathrm{C}$ drop in return temperature below the network average return temperature avoiding reasons for nonachieving low one. The most similar researches related to the DH system monitoring data are covered in Guelpa [28], Luc et al. [29], Saletti et al. [30], Barone et al. [31], and Chicherin \& Anvari-Moghaddam [32].

Variations of actual heat demand profiles are of great importance, which therefore was the objective of previous authors' study [32]. It is based on the analysis of operational data from DH service provider and data recorded at 181 building, all collected during 2020. The methodology involves scaling design heat demand and using the weighted moving average (WMA). In the cases of the coldest weather, the discrepancy of projected and actual values is $7-14 \%$ higher than average one. The study shows the main causes to high discrepancy are following: the variation in the supply line which is about 1.5 times the one in the return line; almost no weather correlation during warm months when supply temperature exceeds $60{ }^{\circ} \mathrm{C}$; thermal inertia affecting the connected buildings differently. Some demand side recommendations are also given; another recommendation is to install central TES. Its size could be defined using given production and heat consumption data. The advantage of the proposed method is by designing TESs or DH plants in accordance with more precise heat demand data, DH operator is able to reduce the energy price through lower infrastructure costs. The proposed strategy has another advantage - to be effective at load shifting - the energy use decreases by 40-50\%. The contribution includes also highlighting 4GDH to have better application prospect in Russia provided that an improved comprehension of heat demands is achieved. Potential solution to resolve that is implementing WMA strategies; advanced control and regulating valves increasing the reliability and reducing the costs.

For the Guelpa's paper [28], the hourly operations of a DH system in Turin, Italy are considered. At the end of the morning and the afternoon, heat consumption varies within a narrow range since the indoor temperature is set at the desired level. During night, energy consumption typically drops. The main two reason are: no DHW use, and smart devices \& TRVs reducing the energy consumption.

The weather data used for Luc et al. [29] paper were the weather data from the Copenhagen, Denmark: design outdoor temperature along with the outdoor temperature recordings from 2016. It was done to elicit the climate data matching the period for which the information on energy generation was available. Outdoor temperature and horizontal solar radiation in the monitored period are then presented to reveal the correlation between weather conditions and heat consumption.

Saletti et al. [30] study optimal control involving operational data by implementing different cost functions and by comparing the results. They use three representative days of January 2017 with time-steps of one hour for Surahammar Municipality (Surahammars kommun) situated in Västmanland County in central Sweden, though similar considerations can be drawn for the other areas.

Barone et al. [31] plot flow rates patterns during the daily hours, which correlate with the recorded energy demand of the DH consumers. The same with us, they detect the minimum flow rates and the maximum temperature values over night-time hours in which no heating demands present (from 23:00 to 5:00). Conclusions are made based on the data set recorded during the winter sample week of January $1^{\text {st }}-7^{\text {th }}$.

The objective of the entire research here is to make a first step towards an integrated approach coupling monitoring methodologies and data processing techniques for supporting designers and operation \& maintenance staff in defining optimal operational mode of a DH system. Consequently, there are two major trends, namely forecasting and optimization with a plenty of support tools, no matter is it for temperature or heat energy consumption. 
Therefore, the aim here is to analyse network supply temperature and heat consumption with an emphasis to routine daily (not design) purposes and provide a link with a DH (CHP) plant operation.

\section{Materials ANd Methods}

Most SH systems in Russia (as in Denmark [33]) are direct-connected ones, which means there is no SH heat exchanger installed, and therefore no temperature degradation, between a DH network and a customer subsystem. This concept includes the special DH water pipe between supply and return lines called bypass. The indirect substation indicates that a plate heat exchanger is used to separate the central heating plant and a consumer.

On the one hand, indirect connection plays a role in differently managing the network and the installed power capacities, in decoupling heat generation and demand and, at the meantime, in providing advantages from the network reliability point of view. On the other hand, due to the heat exchange of hot water at two sides of the plate heat exchangers, a higher supply temperature from a DH system is required to ensure a proper supply temperature at the secondary side. Thus, the hot-water temperature leaving plant is assumed to be $70{ }^{\circ} \mathrm{C}$ or so. Thus, for indirect substations it is recommended to apply efficient heat exchanger in order to decrease the difference between DH supply and SH supply temperature. Proper adjusted control valves ensuring precise control of the SH supply temperature are also highly advisable.

However, in Omsk and Krasnoyarsk the actual coefficient of performance (COP) of a plate heat exchanger is about $5 \%$ lower than the rated one. The configuration of a DHW system tends to require one more heat exchanger. The pressure drop across these two plate heat exchanger is assumed to be $0.2 \mathrm{MPa}$ at least. The discrepancy between the supply and return $\mathrm{DH}$ network temperatures has to ensure warming up to $60{ }^{\circ} \mathrm{C}$ due to Legionella issue. More information on the operation of plate heat exchangers is available in [34].

To make paper readable information is visualized in the form of graphs and charts, orderly and clearly comparing certain points. Some of the data visualized in this way is the data on supply and return temperatures, and heat demand.

The case study is carried out with existing data gathered from information provided by the Omsk and Krasnoyarsk, Russia, heat utility companies [35]. It serves 13373 substations. By changing the degree of openness of the throttle valves, the flow rate of each substation is set to a desired value ample to cover local heat demand. About $90 \%$ of the urban area is residential building and $10 \%$ of that is office building. Moreover, a significant share of multistorey buildings has been built in city so that little ground space can be used for ground source heat pumps [36].

The same with $\mathrm{Wu}$ et al. [8], the energy produced from CHP units covers more than $50 \%$ of the entire system thermal load. The data used in this paper have been elicited from the monitoring system of the DH plants, and then combined with some recent research attempts [37]. In this case study, energy consumption and demands are referred to the buildings consuming energy for space heating and DHW, requested from January $1^{\text {st }}, 2017$ to December $31^{\text {st }}$, 2020. Data for the supply and return temperatures of such buildings is obtained by local SCADA systems equipped by temperature sensors, although the required flow rate for DHW is recorded by small autonomous systems located at each DHW line. The heat consumption and production data is also calculated by heat meters located at consumer substations directly connected to the DH system network whereas, for limiting labour time, while outdoor temperatures are considered for the DH plant location. Moreover, for the sake of simplicity only five different substations in Omsk and Krasnoyarsk are studied thoroughly 
to take into consideration both residential house, and non-residential building. For all the consumers, design indoor temperature of $20^{\circ} \mathrm{C}$ is assumed, whereas additional details about the related heat demand profiles are reported in Results \& Discussion section.

\section{RESUlts AND DiscusSiON}

Figure 1 was made by plotting the steady-state operating points for Omsk DH system at each day.

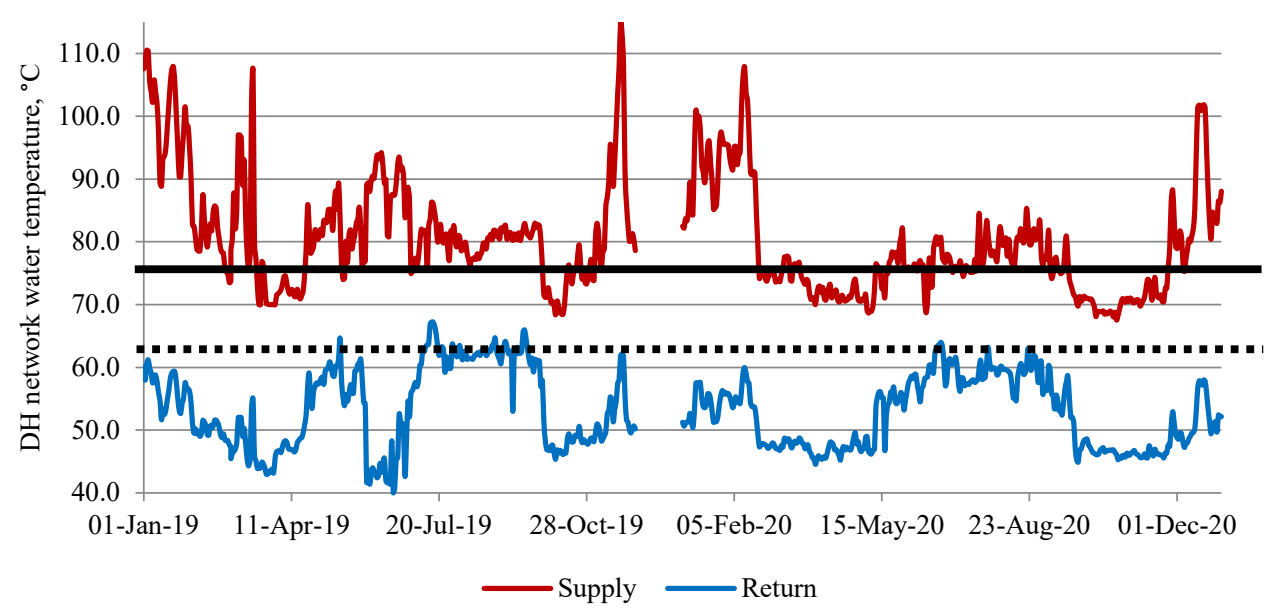

Fig. 1. An effect of weather on supply and return temperatures: they are the highest during cold periods of the year (December and January), although outdoor temperature fluctuations making the whole profile unstable are clearly visible. A black solid line represents value of average supply temperature, while the dashed line is return one.

The supply and return temperatures in a DH system change not only according to the outdoor temperature, but also because of wind, solar radiation, and behaviour of inhabitants using TRV valves. According to the operating data provided by Omsk DH utility company, in winter, the return temperature of the network is lower than $50{ }^{\circ} \mathrm{C}$ in only $50 \%$ or so of the working time. In the rest of the time, the return temperature is between $50{ }^{\circ} \mathrm{C}$ and $60{ }^{\circ} \mathrm{C}$. By comparison, the utility company contracts allow for a $65^{\circ} \mathrm{C}$ minimum supply temperature and a $30^{\circ} \mathrm{C}$ maximum return temperature in the Malmö, Sweden DH network [1]. The potential advantages of this, so called low temperature DH concept are not only decreasing heat losses but also the accessibility to using renewable heat sources and lowgrade waste heat [9].

In Fig. 1, the full and dotted lines indicate operational peak levels of supply $\left(75^{\circ} \mathrm{C}\right)$ and return $\left(62^{\circ} \mathrm{C}\right)$ water temperature from a DH plant to buildings respectively. However, lower supply temperatures without correspondingly lowered return temperatures or lower heat demands lead into a higher flow and therefore electricity consumption to run pumps.

If the supply setpoint is assumed to be constant a widespread Proportional Integrator (PI) controller managing the flow rates at a central level will have a direct effect on the flow rate at a DH plant [25]. Clearly visible state of higher than wherever else return temperatures in Omsk DH system results into the "bottleneck problems" [13], as the flow rate increases. Fig. 2 shows the flow rate for the design conditions, at each respective temperature scenario, over November 2020. 


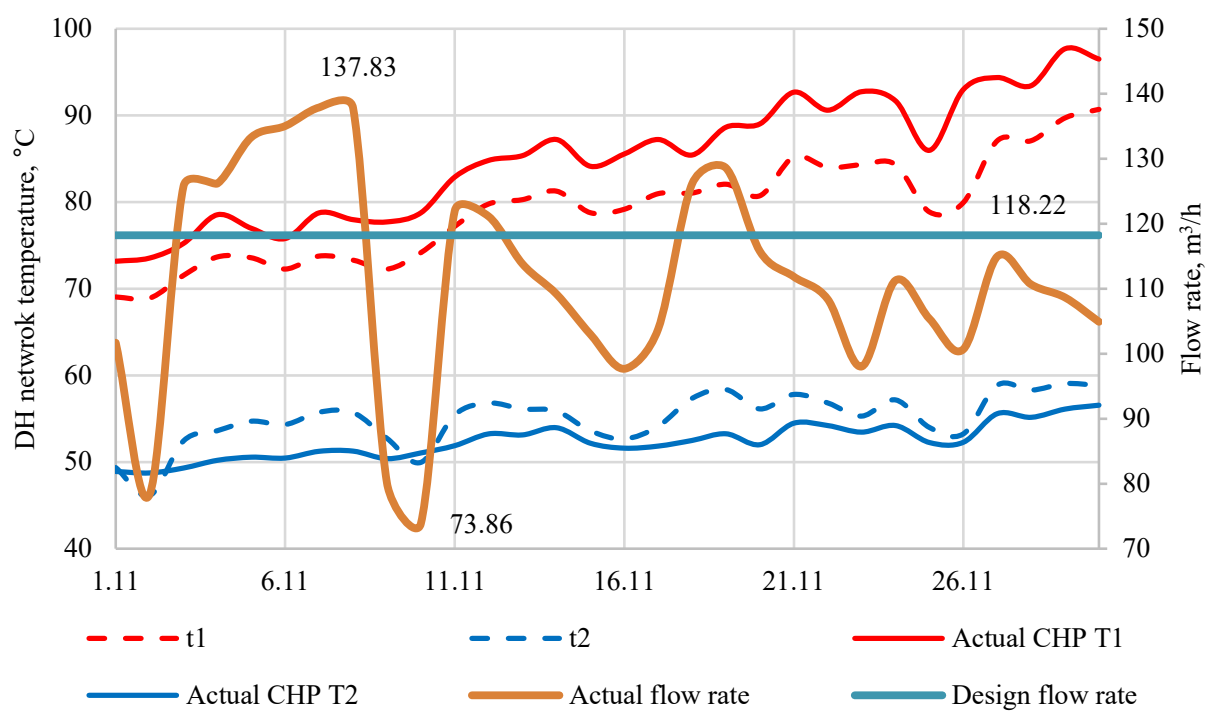

Fig. 2. Temperature and flow rates profiles at a DH substation.

Supply and return temperature difference has a decisive impact on the flow rate and thus lifetime pumping energy cost. From this point of view, temperature difference contributes to the total pressure drop in the network and results into 'bottleneck problems' [13] - limited possibility to expand a DH system and connect new consumers.

This is a question of high importance if lower supply temperatures are introduced without any other renovations in already existing DH areas. In order to shave energy peaks, it is vital to comprehend the behaviours of consumers and identify peak and valleys of different types of buildings [38].

Due to a direct scheme an external bypass is everywhere implemented at a demand side in Krasnoyarsk. It seems to be the main reason for return temperature rise. Temperature degradation happens when heat demands are absent, and the network flow velocities stagnate that results in a supply temperature drop due to heat losses (Fig. 3).

From Fig. 3, lower heat demand results into increasing the mass flow rate. This in turn, acts to reduce heat loss due to barely moving water. Therefore, supply network temperature is the lowest in the night (22:00-7:00) and mid-day (13:00-18:00) as the mass flow rate is lowest at this time period. However, from design point of view, supply temperature is typically a fixed value during day and does not depend on mass flow rate.

This is, however, not something that concerns the property owner (DH consumer), due to there is no motivation to keep temperature difference high or low. Limitations of the most of the regulation methods are that they only consider dynamics to a very limited extent. However, the simulation time in [39] is considerably reduced for model predictive control of real-time applications.

Abovementioned bypass reduces DHW temperature time delays at a substation during nonspace heating periods. Tap delay and hence water consumption on the consumer side (amount to be estimated) can be decreased if solution with a bypass is used. However, additional energy consumption (Fig. 4) and insufficient cooling of DH water might occur. 


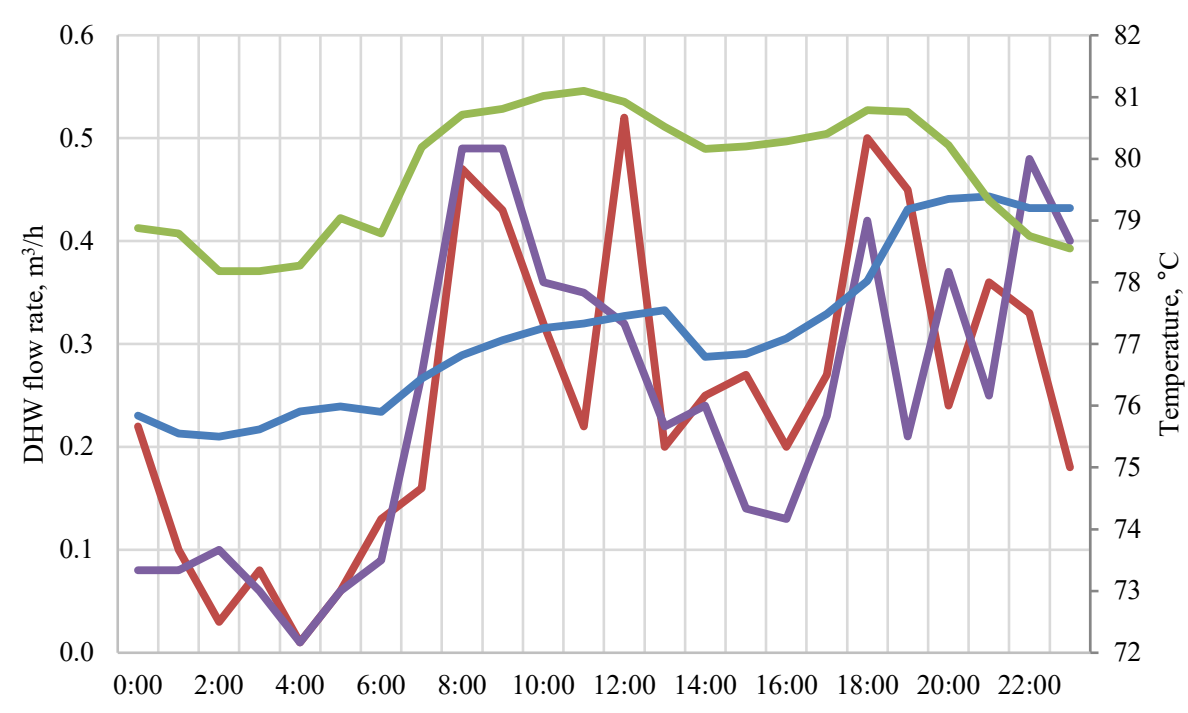

DHW flow rate 11/11

DHW flow rate $12 / 11$

Supply temperature $11 / 11$

Supply temperature $12 / 11$

Fig. 3. DHW flow rate and supply temperatures to a substation.

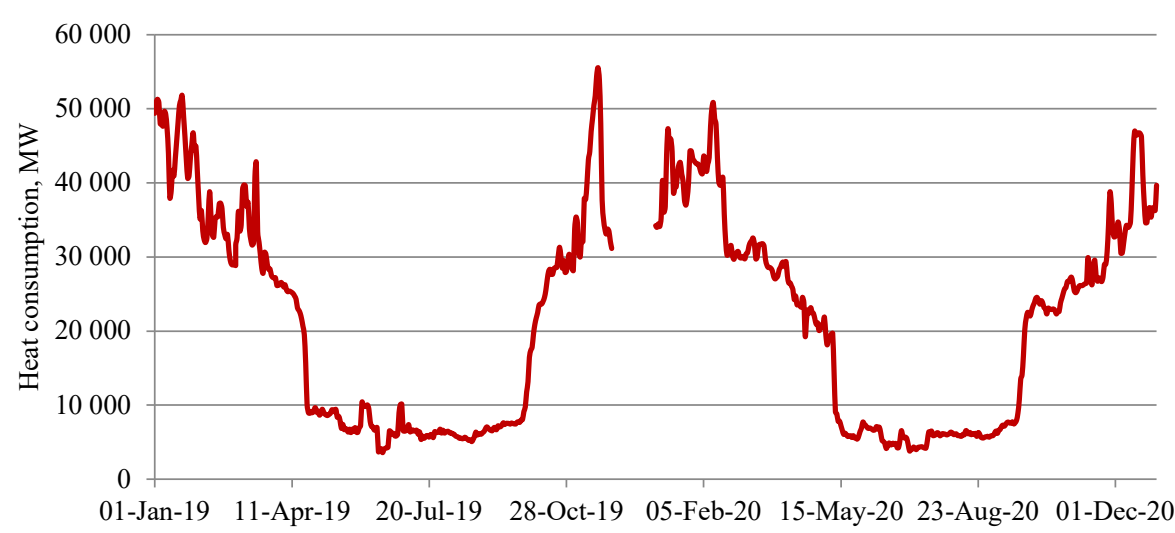

Fig. 4. 2019- and 2020-year consumption.

Peak heat demand in 2019 accounted $55563 \mathrm{MW}$, although in 2020 it was $50082 \mathrm{MW}$. However, peak capacity of $55563 \mathrm{MW}$ is $62.2 \%$ higher than the average value of energy, which was produced during year (21008 MW).

The percentage reduction of the overall primary energy consumption annually is more than $5 \%$, assuming $100 \%$ of consumers connected (corresponding to heating season). When only $67 \%$ of the consumers are served, a reduction of $11.2 \%$ is obtained (non-heating season). It means that the reduction significantly increases when a higher fraction of commercial real estate is considered since most of the office buildings is not provided with DHW in summer. 
The reader is invited to validate values with measured data from the literature, for instance, [40]. It is summarized in Fig. 5, where the similar energy demand profiles with clearly visible yearly valleys and peaks are presented.

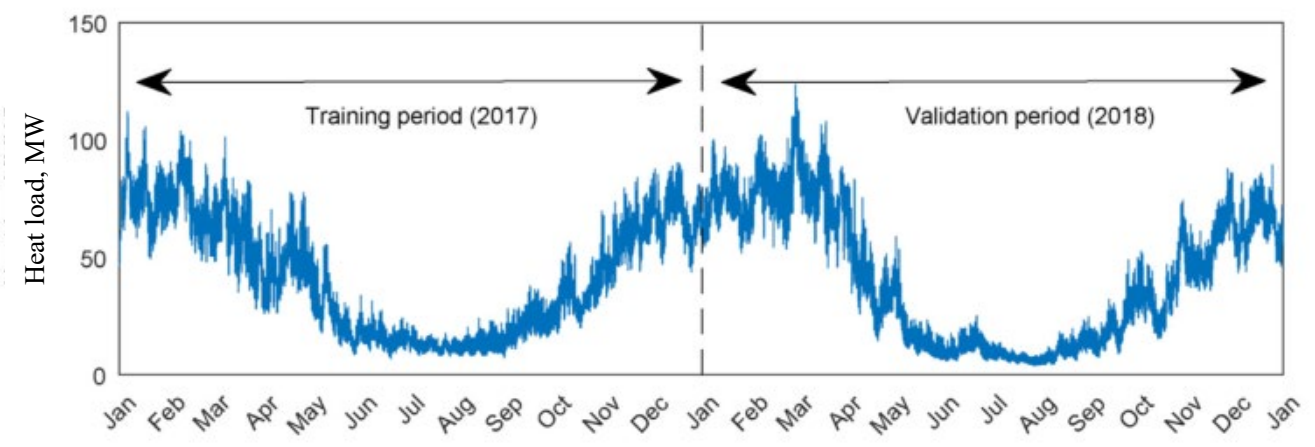

Fig. 5. Monthly time series data of the aggregated heat load of 18475 single family houses by [41].

Moreover, as known [6], the higher the share of commercial buildings, the lower the peak demand and therefore the flatter the load curve. This results in lower (corresponding to an absolute value within a day) volatility during non-heating season than during heating one (Fig. 2). The heat generation duration curves of the CHP plant with constant heat consumption are shown in [42].

The storage capacity is defined using the profiles for the given production and demand profile. Surplus production is defined as the point where energy produced exceeds the sum of energy consumed and distribution losses. This is calculated by allowing all the surplus energy to be dumped into the building envelopes and all the deficit to be supplied by the storage (Fig. 6).

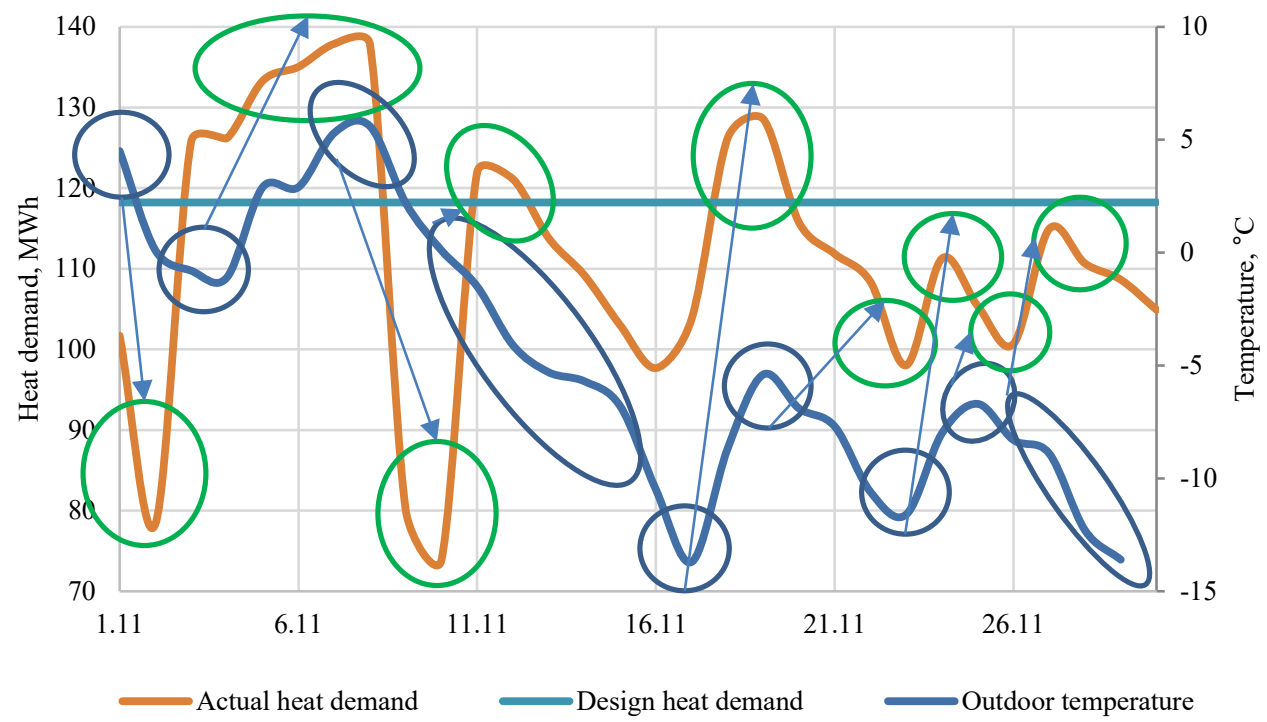

Fig. 6. Correlation between outdoor temperature and heat demand. 
This cycle starts from the outdoor temperature decrease (heating season only). Then, the supply temperature and flow rate increase until the effect goes negative at any certain time step. That means that Omsk and Krasnoyarsk, heat demand strongly correlates with the outdoor temperature, but with some lagging. Now, the heat demand is covered according the maximum storage capacity for the given production and demand profile. Then, the flow rate or supply temperature are varied in the narrower range to find the optimum for the given conditions. Approximately $10 \%$ of energy (surplus amount above the design value) is dissipated for this calculation. Time calls growing with multiple consumption/production scenarios into a multi-level optimization combined with seasonal weather variability ought to be designed to address the planning issues.

Trends in Fig. 7 suggest a generalized decrease of the heat consumption.

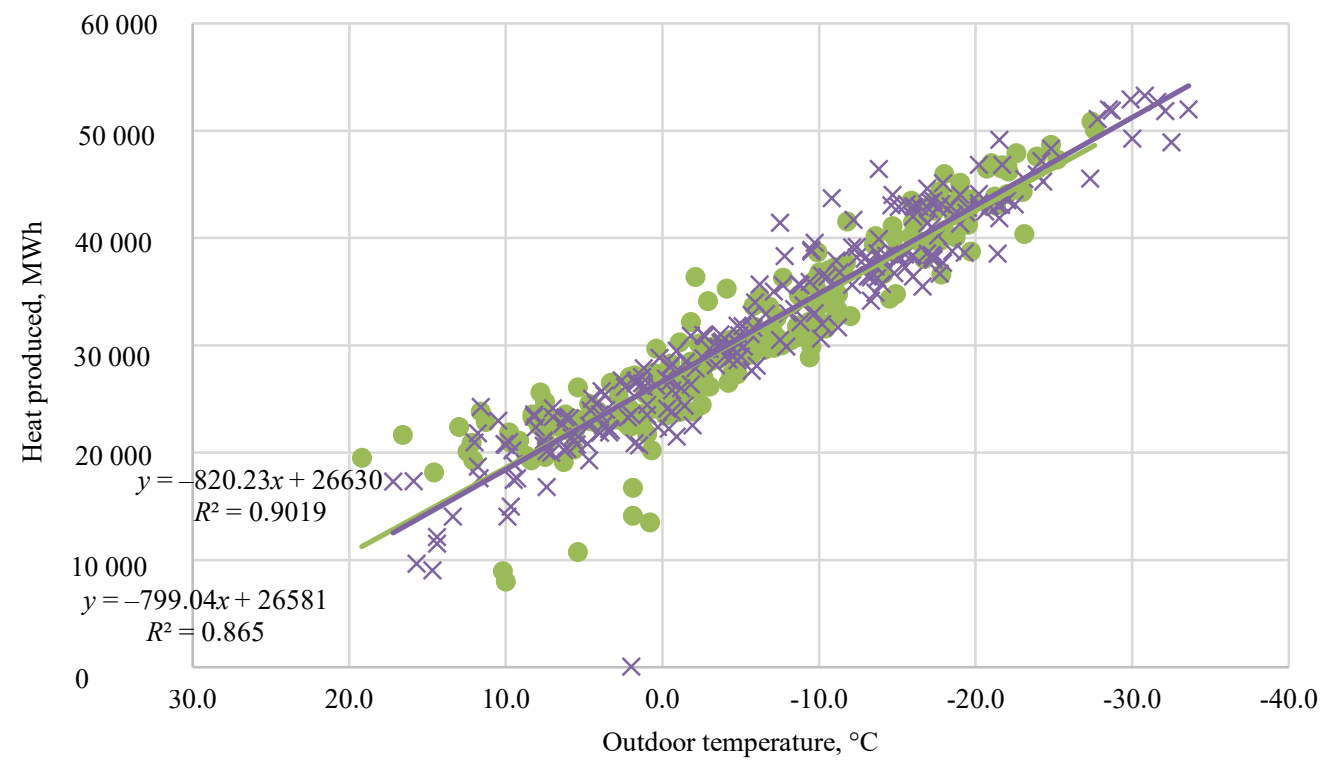

2017-2018 × 2018-2019

Fig. 7. Regression analyses of correlation between outdoor temperature and amount of heat produced.

We found correlation between outside temperature and supply/return temperatures. Based on identified correlation coefficient (0.87-0.9) it is be possible to conclude about the main role of outside temperature on supply and return temperatures in a DH system and limited role of other factors. Besides, over 2 years we see the decrease here, which is represented by $-799.04 t_{\text {out }}+26581$ and $-820.23 \mathrm{t}_{\text {out }}+26630$ curves. However, there are several factors, which may influence the energy performance over two years. There are even more factors, which may have an impact on these analyses in ten years of operation [10].

In 2019, according to the records of the DH utility company, the total heating, DHW, and air conditioning demand was $21008 \mathrm{MW}$. This is more than $5 \%$ than in 2020 . This discrepancy occurs due to:

1. Urban layout plans display that total housing area has diminished (including non-heated space such as $50 \%$ of porch areas and $75 \%$ of loggia areas which can be as much as $5 \%$ of the housing area); 
2. Not all buildings in newly built-up areas of the DH covered zone are connected to the system;

3. Because business facilities can be disconnected from the system if an owner orders it. Meanwhile, plenty of industry and business consumers are connected in Omsk; the same with Krasnoyarsk and Zagreb DH systems [12].

\section{Conclusion}

1. The influence of the future fluctuating energy consumption on a DH system was investigated with an actual data, using the DH system of the Cities of Omsk and Krasnoyarsk as a case study. A reduction in return temperature can be obtained by fewer errors in the network, indirect connection and lower customer temperature demands.

2. Comparison of the recorded data and design inputs of the supply temperatures shows that the proposed model is correct enough to describe $\mathrm{DH}$ plant operating temperature. Relative error of the two supply temperatures varies within $\pm 10 \%$.

3. Technical change refers to enhance DH system functioning, however, the change has not yield lower supply temperatures yet. A novel measure to determine the next day supply temperature is under development. In order to assess energy demand, this is especially helpful in severe weather conditions, where supply temperature tends to change drastically (both Omsk and Krasnoyarsk DH systems).

4. When the primary energy consumption related to the warmer climate and behaviour of business sector decreases, it was revealed that the $\mathrm{DH}$ system needs renovation to reduce heat losses as well as an increase of the operating temperatures to enable lower space heating demand. Based on this conclusion, it may be possible in future to reduce network return temperature during some months.

5. The reason is that, on the system level, a high temperature difference is ultimately essential to maintain a high total efficiency and minimize fuel and electricity cost. An increased temperature difference on system level also enables more customers to be connected to a DH system without increasing pipe dimensions of a DH network.

\section{ACKNOWLEDGEMENT}

The reported study was funded by the Administration of Krasnoyarsk Krai and the Krasnoyarsk Krai Foundation for Support of Scientific and Technical Activity.

\section{REFERENCES}

[1] Brange L., Englund J., Lauenburg P. Prosumers in district heating networks - A Swedish case study. Appl. Energy 2016:164:492-500. https://doi.org/10.1016/j.apenergy.2015.12.020

[2] Chertkov M., Novitsky N. N. Thermal Transients in District Heating Systems. Energy 2018:184:22-33. https://doi.org/10.1016/j.energy.2018.01.049

[3] Zarin Pass R., Wetter M., Piette M. A. A thermodynamic analysis of a novel bidirectional district heating and cooling network. Energy 2018:144:20-30. https://doi.org/10.1016/j.energy.2017.11.122

[4] Averfalk H., Werner S. Novel low temperature heat distribution technology. Energy 2018:145:526-539. https://doi.org/10.1016/j.energy.2017.12.157

[5] Vandermeulen A., et al. A simulation-based evaluation of substation models for network flexibility characterisation in district heating networks. Energy 2020:201:117650. https://doi.org/10.1016/j.energy.2020.117650

[6] Coss S., Verda V., Le-Corre O. Multi-objective optimization of District Heating Network model and assessment of Demand Side Measures using the load deviation index. J. Clean. Prod. 2018:182:338-351. https://doi.org/10.1016/j.jclepro.2018.02.083

[7] Chicherin S. Methodology for analyzing operation data for optimum district heating (DH) system design: Ten-year data of Omsk, Russia. Energy 2020:211:118603. https://doi.org/10.1016/j.energy.2020.118603 
[8] Wu Q., et al. Coupling optimization of urban spatial structure and neighborhood-scale distributed energy systems. Energy 2018:144:472-481. https://doi.org/10.1016/j.energy.2017.12.076

[9] Wang H., et al. Modeling and optimization for hydraulic performance design in multi-source district heating with fluctuating renewables. Energy Convers. Manag. 2018:156:113-129. https://doi.org/10.1016/j.enconman.2017.10.078

[10] Noussan M., Jarre M., Poggio A. Real operation data analysis on district heating load patterns. Energy 2017:129:70 78. https://doi.org/10.1016/j.energy.2017.04.079

[11] Babiarz B., Blokus-Roszkowska A. Probabilistic model of district heating operation process in changeable external conditions. Energy Build. 2015:103:159-165. https://doi.org/10.1016/j.enbuild.2015.06.036

[12] Čulig-Tokić D., et al. Comparative analysis of the District heating systems of two towns in Croatia and Denmark. Energy 2015:92:435-443. https://doi.org/10.1016/j.energy.2015.05.096

[13] Brange L., et al. Bottlenecks in district heating systems and how to address them. Energy Procedia 2017:116:249-259. https://doi.org/10.1016/j.egypro.2017.05.072

[14] Romanchenko D., et al. Impact of electricity price fluctuations on the operation of district heating systems: A case study of district heating in Göteborg, Sweden. Appl. Energy 2017:204:16-30. https://doi.org/10.1016/j.apenergy.2017.06.092

[15] Deng N., et al. Comparative analysis of optimal operation strategies for district heating and cooling system based on design and actual load. Appl. Energy 2017:205:577-588. https://doi.org/10.1016/j.apenergy.2017.07.104

[16] Chicherin S., et al. Method for Assessing Heat Loss in A District Heating Network with A Focus on the State of Insulation and Actual Demand for Useful Energy. Energies 2020:13(17):4505. https://doi.org/10.3390/en13174505

[17] Delangle A., et al. Modelling and optimising the marginal expansion of an existing district heating network. Energy 2017:140:209-223. https://doi.org/10.1016/j.energy.2017.08.066

[18] del Hoyo Arce I. et al. Models for fast modelling of district heating and cooling networks. Renew. Sustain. Energy Rev. 2018:82:1863-1873. https://doi.org/10.1016/j.rser.2017.06.109

[19] Falay B., et al. Enabling large-scale dynamic simulations and reducing model complexity of district heating and cooling systems by aggregation. Energy 2020:209:118410. https://doi.org/10.1016/j.energy.2020.118410

[20] Badami M., et al. Design of district heating networks through an integrated thermo-fluid dynamics and reliability modelling approach. Energy 2018:144:826-838. https://doi.org/10.1016/j.energy.2017.12.071

[21] Dahl M., Brun A., Andresen G. B. Using ensemble weather predictions in district heating operation and load forecasting. Appl. Energy 2017:193:455-465. https://doi.org/10.1016/j.apenergy.2017.02.066

[22] Shan X., Wang P., Lu W. The reliability and availability evaluation of repairable district heating networks under changeable external conditions. Appl. Energy 2017:203:686-695. https://doi.org/10.1016/j.apenergy.2017.06.081

[23] Wang H., Meng H., Zhu T. New model for onsite heat loss state estimation of general district heating network with hourly measurements. Energy Convers. Manag. 2018:157:71-85. https://doi.org/10.1016/j.enconman.2017.11.062

[24] Geysen D., et al. Operational thermal load forecasting in district heating networks using machine learning and expert advice. Energy Build. 2018:162:144-153. https://doi.org/10.1016/j.enbuild.2017.12.042

[25] Claessens B. J., et al. Model-free control of thermostatically controlled loads connected to a district heating network. Energy Build. 2018:159:1-10. https://doi.org/10.1016/j.enbuild.2017.08.052

[26] Valinčius M., Vaišnoras M., Kaliatka A. Study and demonstration of pressure wave-based leak detection in a district heating network. Struct. Infrastruct. Eng. 2018:14:151-162. https://doi.org/10.1080/15732479.2017.1330892

[27] Tunzi M., et al. Improving thermal performance of an existing UK district heat network: A case for temperature optimization. Energy Build. 2018:158:1576-1585. https://doi.org/10.1016/j.enbuild.2017.11.049

[28] Guelpa E. Impact of thermal masses on the peak load in district heating systems. Energy 2021:214(1):118849. https://doi.org/10.1016/j.energy.2020.118849

[29] Luc K. M., et al. Energy flexibility potential of a small district connected to a district heating system. Energy Build. 2020:225:110074. https://doi.org/10.1016/j.enbuild.2020.110074

[30] Saletti C., et al. Enabling smart control by optimally managing the State of Charge of district heating networks. Appl. Energy 2021:283:116286. https://doi.org/10.1016/j.apenergy.2020.116286

[31] Barone G., et al. A novel dynamic simulation model for the thermo-economic analysis and optimisation of district heating systems. Energy Convers. Manag. 2020:220:113052. https://doi.org/10.1016/j.enconman.2020.113052

[32] Chicherin S., Anvari-Moghaddam A. Adjusting Heat Demands Using the Operational Data of District Heating Systems. Energy 2021:235:121368. https://doi.org/10.1016/j.energy.2021.121368

[33] Farouq S., et al. Large-scale monitoring of operationally diverse district heating substations: A reference-group based approach. Eng. Appl. Artif. Intell. 2020:90:103492. https://doi.org/10.1016/j.engappai.2020.103492

[34] Wang Y., et al. Operation stability analysis of district heating substation from the control perspective. Energy Build. 2017:154:373-390. https://doi.org/10.1016/j.enbuild.2017.08.034

[35] Chicherin S., et al. Optimizing Industrial Facility's Demand for Combined Heat-and-Power (CHP). Sustainable Development of Water and Environment. Springer, 2020:287-295.

[36] Sartor K., Lemort V., Dewallef P. Improved district heating network operation by the integration of high-temperature heat pumps. Int. J. Sustain. Energy 2018:37(9):842-856. https://doi.org/10.1080/14786451.2017.1383409

[37] Chicherin S., et al. Comparing strategies for improving thermal performance of an existing district heating (DH) network: low temperature DH in Omsk, Russia. E3S Web Conf. 2020:173:03001. https://doi.org/10.1051/e3sconf/202017303001 
[38] Chicherin S., Junussova L., Junussov, T. Advanced Control of a District Heating System with High Residential Domestic Hot Water Demand. E3S Web Conf. 2020:160:01004. https://doi.org/10.1051/e3sconf/202016001004

[39] Schweiger G., et al. Framework for dynamic optimization of district heating systems using Optimica Compiler Toolkit. Proceedings of the 12th International Modelica Conference 2017:131-139. https://doi.org/10.3384/ecp17132131

[40] Jangsten M., et al. Survey of radiator temperatures in buildings supplied by district heating. Energy 2017:137:292301. https://doi.org/10.1016/j.energy.2017.07.017

[41] Kristensen M. H., Hedegaard R. E., Petersen S. Long-term forecasting of hourly district heating loads in urban areas using hierarchical archetype modeling. Energy 2020:201:117687. https://doi.org/10.1016/j.energy.2020.117687

[42] Romanchenko D., et al. Thermal energy storage in district heating: Centralised storage vs. storage in thermal inertia of buildings. Energy Convers. Manag. 2018:162:26-38. https://doi.org/10.1016/j.enconman.2018.01.068 